\title{
Failure to thrive in a population context: two contrasting studies of feeding and nutritional status
}

\author{
Charlotte Wright*, Jane Loughridge and Gill Moore \\ Community Child Health Unit, Donald Court House, 13 Walker Terrace, Gateshead NE8 1EB, UK
}

\begin{abstract}
Although failure to thrive (FTT) is generally thought to be a nutritional problem, dietary intake in children with FTT has been little researched. We describe two community-based studies of dietary intake and eating behaviour in FTT. The first study of ninety-seven children with FTT identified by population screening found that only a minority of case children were associated with neglect, organic illness or deprivation, even though dietary information suggested an underlying nutritional cause in the majority. Limited case-control data suggested significantly delayed weaning and less liking for food in general among the case children. The second study found diminished appetite, delayed progression onto solid foods and fewer foods eaten by forty-four children referred with FTT compared with forty-five controls, but was unable to detect a significant difference in energy intake, even allowing for varying body composition and other confounding variables. This study also revealed the bias introduced by recruiting case children by referral rather than screening, and that despite rigorous matching procedures the controls were not representative of the general population. These studies suggest a wide range of differences in eating behaviour and feeding patterns between children with FTT and controls, but suggest that measurements of nutrient totals may not be robust. Studies of FTT based on referred children can be misleading, as can comparison with controls, unless allowance can be made for important confounding social variables.
\end{abstract}

Failure to thrive: Infants: Feeding behaviour

It is recognized that failure to thrive (FTT) in infancy is usually the result of relative undernutrition (Skuse, 1985). However, surprisingly little research has been conducted into the nutritional status of these children. Most children with FTT have been found to be substantially under their weight-for-height (Drotar et al. 1985; Skuse et al. 1992; Black et al. 1995; Wright \& Birks, 1999), and improved weight gain has been demonstrated in FTT children subjected to dietary interventions (Bithoney et al. 1989; Wright et al. 1998b). However, there have been few direct studies of dietary intake.

All research in FTT has been complicated by two particular methodological problems: varying definitions and referral bias. Nutritional studies then face the additional challenge of estimating energy requirements in 'free-living' children who also have a body composition very different from the norm.

\section{The definition of failure to thrive}

Until recently there was no uniformity in the diagnostic criteria for FTT, with different researchers using a range of composite definitions. These definitions all too often incorporated a subjective component such as "children with slow but persistent weight patterns suggesting constitutional growth patterns were not included' (Drotar \& Sturm, 1988). The most easily applied criteria, definitions that require children to be below a certain low centile, provide only an indirect measure of actual weight gain, and will always include an over-representation of relatively small children.

Our group has developed a definition based on a fall down a centile chart, rather than centile position alone. We have characterized the pattern and range of centile shift in the first 18 months, as well as the influence of initial centile position (Wright et al. 1994). This procedure revealed that

\footnotetext{
Abbreviations: FTT, failure to thrive; SDS, standard deviation score; TI, thrive index.

*Corresponding author: Dr Charlotte Wright, fax +44 (0)191 4770370, email c.m.wright@ncl.ac.uk
} 
only $5 \%$ of children growing within the normal range dropped through more than two weight centile spaces $(\approx 1.3$ SD scores) from their average centile position tracked up to the age of 8 weeks. However, at the extremes very large infants will always tend to fall towards average, while small infants tend to rise: the phenomenon of regression to the mean. This pattern can be characterized using the thrive index (TI; Wright et al. 1994):

$$
\begin{aligned}
& \mathrm{TI}=\text { weight standard deviation score }(\mathrm{SDS})_{\text {late }}-\text { expected } \\
& \text { weight SDS, } \\
& \text { where } \\
& \text { expected weight SDS }=\text { weight } \mathrm{SDS}_{\text {initial }} \times \text { constant }
\end{aligned}
$$

This constant varies depending on the exact timing of the earlier and later SDS, and corresponds to the regression coefficient for that time interval. The TI thus constitutes a continuous measure of thriving, with automatic adjustment for regression to the mean. For clinical purposes the adjustment has been incorporated into a specialist growth chart (Fig. 1; Wright et al. 1998a).

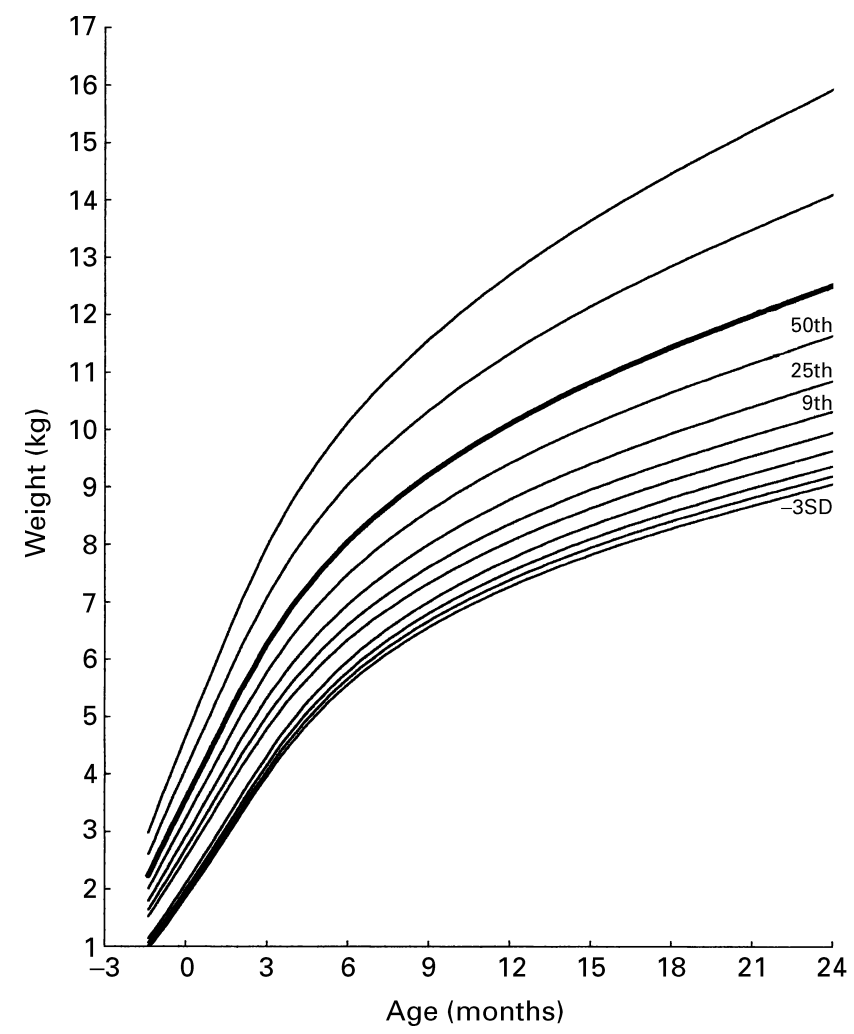

Fig. 1. The weight monitoring chart: a specialist growth chart incorporating adjustment for regression to the mean; for details, see pp. 37-38. When is a fall abnormal? Crossing completely through two channel widths (space between two solid lines) from the baseline position (average channel position tracked between birth and 8 weeks) occurs in only $5 \%$ of normal children and usually suggests moderate failure to thrive. Only $1 \%$ of normal children will cross through three to four channel widths, suggesting severe failure to thrive. Subsequent catch-up to within one channel of baseline constitutes recovery. (From Wright et al. 1998a.)

\section{Referral bias}

Most early research into FTT studied children referred to hospital for assessment, which always carries a risk of referral bias. This bias all too often produces a distorted distribution of important risk factors, most notably social class. This distortion was well demonstrated for FTT in a study of well-baby clinic records (Batchelor \& Kerslake, 1990), which identified all the children in the clinic population who were below the 3 rd centile. The study showed that approximately half these children had been labelled 'non-organic FTT' and half 'short normal'. Those children labelled FTT were much more socially disadvantaged, even though their subsequent growth data was not distinguishable from that of children labelled short normal.

The solution to this problem is to undertake wholepopulation screening. A few such studies have been undertaken (Dowdney et al. 1987; Skuse et al. 1994; Wilensky et al. 1996), but even fewer studies have included any sort of dietary assessment (Heptinstall et al. 1987). For our programme of work in Newcastle we established a district-wide screening programme to allow the identification of all children meeting the screening definition of FTT, without the necessity of formal referral. Cases were identified using the routine child surveillance programme, with health visitors submitting weights to the child health computer at 6-8 weeks and at least once thereafter before the age of 18 months.

\section{Estimating energy requirements}

Assessing energy intake in FTT presents a number of challenges. First, intake must be calculated from diaries completed by a third party, with allowance made for complications such as breast feeds or food thrown onto the floor. Once these totals have been obtained, they must then be related to the child's expected energy requirements. This procedure presents particular problems in FTT, since the main determinant of energy needs is lean body mass. Infants with FTT usually have a very different body composition from normal infants, with lean body mass representing a much higher percentage of total body mass than that of normally-growing infants. This variance probably explains why previous studies (Pollitt \& Leibel, 1980; Heptinstall et al. 1987), although finding lower total energy intakes in children with FTT, found that the intake on a per $\mathrm{kg}$ body weight basis was higher than that of the controls.

The present paper will discuss our programme of investigation into FTT, concentrating on two studies. The first study described the social and dietary characteristics of a clearly-defined and unselected population of children with FTT, with only limited control comparisons, while the second study, a formal case-control study, tested the hypotheses generated by the first study. Both studies used various common approaches.

\section{Screening definition used}

The threshold criterion used to define children as cases for the purposes of both studies was a TI of <-1.3 weight SDS, 
i.e. a fall through two centile spaces since the early weeks, adjusted for regression to the mean. This criterion identifies the slowest gaining $5 \%$ of children, whatever their initial weight centile.

\section{Assessment method}

The assessment was undertaken by the child's own health visitor, supported by a multi-disciplinary team (The Parkin Project) which included specialist paediatric dietitians, paediatricians and social workers. Since field health visitors collected much of the basic information, a simple, brief and relevant assessment protocol had to be employed. The health visitors completed an assessment pro forma, documenting family information and the child's medical and dietary history, as well as representative weights since birth.

\section{Study 1. The Parkin Project}

This project involved a study of a cohort of children with FTT identified by population screening, as part of a randomized trial of community-based intervention in FTT (Wright \& Birks, 1999). Using the computerized surveillance programme described earlier (p. 38), all children meeting our screening threshold for FTT were identified in the district. Half the primary care teams in Newcastle city (randomly selected) were involved in the intervention, while children in the other practices acted as untreated controls.

Those children in the intervention group underwent a standardized assessment as described earlier (p. 38), and it is the results for these children only that are presented here. After assessment by the health visitor the family completed a $3 \mathrm{~d}$ food diary, which was usually checked at a home visit by the project dietitian. Tailored advice was usually then offered with a view to increasing the energy content of the child's diet; dietary supplements were not used. Unless there was active hospital involvement, a medical examination by the project paediatrician was then offered at which weight, length and parental heights were measured. After this examination the health visitor monitored the family, forwarding weights to the project team until recovery. The great majority of the children were managed entirely at home. The results of the assessment by the health visitor were compared with responses obtained by a research health visitor from a small group of normally-growing control children aged 16-18 months, systematically sampled from three representative city practices, using the child health register (Wright \& Birks, 1999). Demographic data were also compared with census data for Newcastle city and to regional feeding survey information (Office of Population Censuses and Surveys, 1992; Foster et al. 1997) Ethical approval for the study was obtained from Newcastle and North Tyneside Combined Ethical Committee.

\section{Analysis}

Before data entry, the clinical notes were reviewed by C.M.W. and C Aves (paediatric dietitian for the study) and the overall strength of the history of undernutrition rated as: clear (a history of dietary insufficiency which would be obvious to any child health practitioner); probable (a history which would indicate undernutrition to a paediatric dietitian); possible (hints or suggestions of insufficiency only); none (where some assessment had been made, but no evidence was found). In addition, weight gain around the time of dietary interview or other dietary intervention was examined by calculating the change in weight SDS following input. A downward trend before intervention followed by an upward trend immediately afterwards was classified as a positive response to dietary advice. Finally, the energy totals from the food diary were calculated using Microdiet (Fletcher, 1994) and used to generate total nutrient intake compared with estimated average requirements (Department of Health, 1994). The overall evidence found for undernutrition in each child was then summarized by means of a formal rating system, the nutrition score, that utilized the three main strands of dietary information (Table 1).

Table 1. Study 1. The nutrition score: overall evidence of undernutrition in ninety-seven population screened cases of failure to thrive

\begin{tabular}{|c|c|c|c|c|}
\hline Score & Category & Criteria & No. of cases & Percentage of total \\
\hline 1 & Strong evidence & $\begin{array}{l}\text { The presence of one of the following: } \\
\text { Clear history of undernutrition } \\
\text { Energy intake less than } 70 \% \text { of predicted } \\
\text { Clear weight gain response to dietary advice }\end{array}$ & 31 & 32 \\
\hline 2 & $\begin{array}{l}\text { Moderate evidence (more than } \\
\text { one source) }\end{array}$ & $\begin{array}{l}\text { Two or more of the following: } \\
\text { Moderate or possible history of undernutrition } \\
\text { Energy intake } 70-90 \% \text { of expected } \\
\text { Possible weight gain response to dietary advice }\end{array}$ & 14 & 14 \\
\hline 3 & Moderate evidence (one source) & $\begin{array}{l}\text { Presence of one only of the following: } \\
\text { Moderate history of undernutrition } \\
\text { Energy intake } 70-80 \% \text { of expected } \\
\text { Possible weight gain response to dietary advice }\end{array}$ & 19 & 20 \\
\hline 4 & Possible & $\begin{array}{l}\text { Presence of one only of the following: } \\
\text { Possible history of undernutrition } \\
\text { Energy intake of } 80-90 \% \text { expected }\end{array}$ & 19 & 20 \\
\hline 5 & $\begin{array}{l}\text { No evidence } \\
\text { Not assessed }\end{array}$ & None of the above & $\begin{array}{r}2 \\
12\end{array}$ & $\begin{array}{r}2 \\
12\end{array}$ \\
\hline
\end{tabular}




\section{Results}

Recruitment to the study took place over 2 years. There were 122 children who were identified as FTT by screening in participating practices. After exclusion of twin siblings and children making early recoveries, ninety-seven children were eligible for assessment. Of these, ninety-four families (97\%) completed assessment at a median age of 15 months. There were forty eligible control children in the target agerange (16-18 months) in the three practices, and the mothers of twenty-eight ( $70 \%)$ of them agreed to be interviewed.

Seventeen of the case children $(17.5 \%)$ had relevant organic conditions, but in only four cases were these the main explanation for their FTT. The case families had very similar levels of deprivation to both the controls and Newcastle city norms (Table 2). Over the period of followup twenty-one $(22 \%)$ families received some social work input, but this input resulted in only four children being registered as being at risk of abuse or neglect, of whom three children went into care.

The case families had similar levels of breast-feeding compared with both the controls and local norms (Table 2). Their mean age at weaning (3.9 (SD 1.3) months was close to national recommendations. However, weaning was nearly 1 month later than that in the controls (3.0 (SD 1.1) months; $P=0.003 ; t$ test $)$, an age much more comparable with local norms $(62 \%$ children in the northern region have commenced feeding on solids by the age of 3 months; Foster et al. 1997). A similar difference was seen for the age of starting finger foods. The comparative data also suggested that the case children were more likely to have had early feeding problems, were less likely to be hungry for meals and to like all foods significantly less (Wright \& Birks, 1999).

The weights of the case children were markedly subnormal, and their lengths less so (mean weight SDS -2.00 (SD 0.93), length SDS -1.06 (SD 0.96)). These lengths were on average $0.5 \mathrm{SD}$ lower than their mid-parental heights, with one-third being more than 1SD below midparental heights. Most case children were markedly underweight for their height, with only sixteen (16\%) having BMI values above the 10th percentile. The case children had shown a maximum mean fall of -2.17 (SD 0.56) SDS, with the steepest rate of fall before 6 months, and a plateau reached at approximately 1 year of age. During follow-up ninety-six $(99 \%)$ of the case children showed catch-up weight gain at some point and eighty-five $(88 \%)$ showed sustained improvement.

Seventy-seven case families (79 \%) completed food diaries and fifty-nine $(61 \%)$ were seen in person by the project dietitian. A clear history of undernutrition was found in thirteen $(13.4 \%$ ) cases and a probable history in a further thirty-nine (40\%); possible $20(22 \%)$, none $18(19 \%)$, no history obtained $7(7 \%)$ ). Of seventy-three food diaries which yielded enough information for energy intake to be calculated, eleven $(15 \%)$ showed energy intakes of less than $70 \%$ of the estimated average requirements and a further sixteen $(22 \%)$ diaries revealed energy intakes of between 70 and $80 \%$ of the estimated average requirements. Thirty children $(41 \%)$ had energy intakes apparently well within the normal range (>90\% estimated average requirements), but of these diaries five appeared to be fabricated, while

Table 2. Studies 1 and 2. Baseline characteristics of children with failure to thrive (cases) and control children and their families from Newcastle city

\begin{tabular}{|c|c|c|c|c|c|c|c|c|}
\hline & & \multicolumn{3}{|c|}{ Study 1} & \multicolumn{3}{|c|}{ Study 2} & \multirow[b]{2}{*}{ Newcastle city§ } \\
\hline & & Cases & Control & $\begin{array}{c}\text { Statistical } \\
\text { significance of } \\
\text { difference: } \\
\mathrm{P \dagger}\end{array}$ & Cases & Control & $\begin{array}{c}\text { Statistical } \\
\text { significance of } \\
\text { difference: } \\
P \dagger\end{array}$ & \\
\hline \multirow{2}{*}{\multicolumn{2}{|c|}{$\begin{array}{r}\text { Age at assessment: } \begin{array}{r}\text { Median } \\
\text { Range }\end{array}\end{array}$}} & $15 \cdot 1$ & 17 & NS $\ddagger$ & 14.9 & $17 \cdot 4$ & NS $\ddagger$ & \\
\hline & & $7-28$ & $16-18$ & & $6-32$ & $7-33$ & & \\
\hline \multirow[t]{2}{*}{ Males: } & No. & 52 & 17 & NS $\ddagger$ & 19 & 22 & NS $\ddagger$ & \\
\hline & $\%$ total & 54 & 61 & & 43 & 49 & & \\
\hline \multirow{2}{*}{ Deprivation score*: } & Mean & 1.43 & 1.5 & NS $\ddagger$ & 1.5 & 0.73 & $0.001 \ddagger$ & \\
\hline & SD & $1 \cdot 27$ & $1 \cdot 29$ & & $1 \cdot 3$ & 0.9 & & \\
\hline \multicolumn{2}{|c|}{ No employed parent:No. } & 39 & 13 & NS & 19 & 8 & 0.007 & \\
\hline & $\%$ total & 42 & 46 & & 44 & 18 & & $29 \|$ \\
\hline \multirow[t]{2}{*}{ Not home owners: } & No. & 52 & 15 & NS & 29 & 13 & 0.0002 & \\
\hline & $\%$ total & 55 & 54 & & 67 & 29 & & 54 \\
\hline \multirow[t]{2}{*}{ Not car owners: } & No. & 43 & 14 & NS & 20 & 12 & 0.05 & \\
\hline & $\%$ total & 48 & 50 & & 46 & 27 & & 49 \\
\hline \multirow[t]{2}{*}{ Non-Caucasian: } & No. & 9 & 0 & NS & 2 & 2 & NS & \\
\hline & $\%$ total & $9 \cdot 4$ & & & 5 & 5 & & $9 \cdot 4$ \\
\hline \multirow[t]{2}{*}{ Ever breast-fed: } & No. & 45 & 14 & NS & 11 & 30 & 0.0001 & \\
\hline & $\%$ total & 46 & 50 & & 25 & 67 & & $56^{\star \star}$ \\
\hline \multicolumn{2}{|l|}{ Total no. } & 97 & 28 & & 44 & 45 & & \\
\hline
\end{tabular}

*Generated using one point each for: no employed member of the household; no car; rented or council accommodation.

†Chi-squared test.

$\ddagger t$ test.

$\S$ Families with children $<5$ years of age (Office of Population Censuses and Surveys, 1992).

$\|$ Families with children $<15$ years of age.

${ }^{\star *}$ Rate for northern region (Foster et al. 1997). 
seven were from children who by then had already caught up to above the screening threshold. Seventeen (18\%) children showed immediate growth responses to dietary advice and three showed possible responses.

Use of the nutrition score to combine the earlier information suggested that thirty-one children (32\%) had strong evidence of undernutrition. Only fourteen children showed no evidence of undernutrition, of whom only one had been fully assessed (Table 1). The nutrition score, used as a continuous variable, correlated significantly with BMI $(R 0 \cdot 28, P<0 \cdot 05)$ as well as with severity of FTT (TI) at the time of assessment $(R 0.29, P<0.01)$.

\section{Discussion}

We thus found that screening for slow weight gain identified children who were markedly underweight for their height and who predominantly showed subsequent catch-up growth, sometimes immediately following dietary advice. The majority of the children were from 'normal' families and did not have significant organic disease, but moderate evidence of undernutrition was found in two-thirds of the children.

However, there is no comparative information on the dietary data, which was itself not complete for all children. The comparisons that could be made must be viewed with caution: the controls were drawn from a much narrower agerange and were selected from just two general practices, although these controls did prove to be comparable with city norms. What this study did do was shed light on the sort of findings that may be observed in a real-life setting. These findings suggest that while only a minority of children with slow weight gain will have dietary histories that are obviously inadequate, wider ranging nutritional assessment may be more revealing.

As a result of these limitations, once the trial had been completed we undertook a second study to try to obtain more consistent dietary information and compare it with matched controls.

\section{Study 2. Dietary assessment in failure to thrive: a case-control study}

This study set out to address the following specific hypotheses, generated from the first study, that children with failure to thrive, compared with normally-growing controls would:

1. consume less food, with less variety;

2. have been weaned significantly later and show an immature feeding pattern;

3 . have had higher rates of early feeding difficulty as well as less current interest in food.

\section{Subjects}

By the time of this study the intervention programme was integrated into normal service activities. Thus, although whole-population weight screening continued, health visitors could now choose whether or not to involve the Parkin Project. Cases included were thus those children referred over a 2-year period who received dietetic assessment and who met our diagnostic criterion for FTT at that time. In the first year, only children aged between 12 and 24 months were recruited because of a linked behavioural study. In the second year all referrals agreeing to dietary assessment were included.

As each new case was recruited, the five children who were nearest in age to the case, in the same general practitioner practice and of the same sex were identified from the district child health computer. Letters were sent to all five families asking if they would be willing to participate. On receipt of replies, the respondent geographically nearest to the case was selected for study as a control. If no replies were received, families were visited at home and invited to participate, starting with the geographically nearest, until a family consented.

\section{Measures}

Data for the study were obtained from the standard health visitor assessment pro forma, a $3 \mathrm{~d}$ food diary and routinelycollected anthropometric measurements.

The assessment pro forma used was a refined version of the original pro forma. It included information about the family structure, questions on previous and present feeding patterns, an outline of food and drink offered in a typical day and a food-frequency table with thirty-six items.

For case children the assessment pro forma was completed by the health visitors, who then supplied families with a $3 \mathrm{~d}$ food diary. On completion of the diary, the paediatric dietitian visited the family, discussed the contents of the diary, and offered dietary advice as appropriate. Previous routinely-collected weights were retrieved from the child's health visitor for all case children, including the weight nearest to the 6-week check and the last weight recorded immediately before the dietitian's visit.

Control families were asked, when recruited, to keep a $3 \mathrm{~d}$ food diary. They were then visited at home by one of three project dietitians, where the assessment pro forma was completed and the contents of the diary verified. The weight nearest to the age of 6 weeks and the most recently recorded weight of the child was also retrieved from their personal child health record. Ethical approval for the study was obtained from Newcastle and North Tyneside Combined Ethical Committee.

\section{Adjustment for confounding}

Unlike the previous study, this group of children had been referred for assessment and would not necessarily be representative of all children with FTT. Although it was hoped that geographical proximity would effect some socioeconomic matching of controls, this could not be relied on entirely. Thus, the assessment pro forma included three questions which allowed the generation of a deprivation score with one point each for: no employed member of household; no car; rented or council accommodation. 


\section{Analysis}

All weights for case and control children were converted into SDS compared with UK 1990 standards (Freeman et al. 1995). The SDS at age 6 weeks was used to calculate the expected SDS (expected $\mathrm{SDS}=\mathrm{SDS}_{6}$ weeks $\times 0.65$ ). This value was compared with the actual weight SDS at assessment to calculate the TI.

The contents of the $3 \mathrm{~d}$ food diaries were analysed using Microdiet (Fletcher, 1994) to obtain macro- and micronutrient totals. As a result of the difficulty in adjusting energy intake for lean body mass in a group of children with much reduced percentage body fat, two different denominators were used. First, we calculated energy intake on an expected weight-for-height basis: i.e. the weight-forage corresponding to the child's height SDS at the age assessed. This procedure would be expected to provide a relative underestimate of true requirements, since a proportion of the children were probably already stunted due to undernutrition. In the controls only, if the height SDS was not available, their actual weight was used instead, on the presumption that they would have an approximately normal weight-for-height.

Second, we used their expected weight-for-age had they not shown slowed weight gain, calculated from the expected weight SDS used as the baseline when calculating the TI. The problem with this procedure is that it assumes that all the decline among case children is the result of undernutrition, with no constitutional element. Thus, this approach is inherently biased towards detecting a difference between case and control children. We thus chose to use both approaches, in the hope that this procedure would provide some idea of the true range.

A paired analytical approach was not used, as the matching was not close and so would preclude adjustment for confounding. The data were analysed initially using Chi-squared, $t$ test for normally distributed data and Mann Whitney for skewed data. Where variables showed associations at $P<0.1$ with potential confounders, they were entered into logistic and multiple linear regression models, but removed again unless attaining significance levels of $P<0.05$.

\section{Results}

Forty-four case children who met the strict criteria for FTT were recruited over the 2-year period. Forty-two case children had made a fall (TI) of $<-1 \cdot 3$ SD since the age of 6 weeks, and the other two case children had fallen from their average SDS position between birth and 8 weeks. One case child had been born at 32 weeks and her growth data were corrected for prematurity.

Forty-five controls were recruited and studied. Thirtynine of these children had both early and late weights, and could be shown to have weight gain within normal limits over that time period. Six children lacked early weights for comparison, but all had assessment weights within the normal range. It proved surprisingly difficult to contact potential controls, and several visits were often required before a family was found that was willing to participate. The result of this difficulty was first that the mean age by which controls were studied was 17 months compared with 15 months for the case children (Table 2). Second, it became apparent early in the analysis that there were important demographic differences between case and control children. Controls were significantly more affluent than both case children and city norms, while case children were markedly less likely to have been breast-fed than controls and regional norms (Table 1). Since breast-feeding is known to be associated with a number of markers of 'good' parenting, mode of milk feeding was treated as a potential confounder, as well as deprivation score and age.

\section{Amount and variety of foods eaten}

When energy intakes were compared, as expected, case children consumed slightly more energy on an actual weight basis than the controls. However, intake calculated on an expected weight-for-height basis was only slightly lower. Even intake calculated on the basis of predicted weight based on early-weight SDS, although lower, was still not quite significant (Table 3). Similar results were seen when other nutrients, such as protein, were examined.

Two estimates of the number of different foods consumed were available: the number of different food types the mother reported giving in the food-frequency tables and the number of distinct foods recorded in the $3 \mathrm{~d}$ food diet. In contrast to the energy totals, the number of foods eaten, both in the diary and as reported in the food-frequency table were significantly lower in the case children even after adjustment for confounding by age (Table 3 )

\section{Eating behaviour and maturation}

Univariate analysis showed that early feeding problems were much more common in case children, but this factor was also strongly related to mode of feeding and was no longer significant on multivariate analysis. Case children and their mothers were slightly less likely to enjoy meal-times than controls, but significantly less likely to be hungry for meals or to eat all food offered (Table 4). Case children had been introduced to solids slightly later than controls, but the difference was not significant (median age (months): case children $3 \cdot 5$ (range 1.5-9.0), controls $3 \cdot 0$ (range 1.5-6.0); $P=0.6$; Mann Whitney). However, case children had started finger foods significantly later (median age (months): case children 7.0 (range 5-12), controls 6.0 (range 4-9.5); $P=0.027$; Mann Whitney). Neither variable was significantly related to either deprivation score or breast-feeding. Case children were significantly less likely to have started using a drinking beaker rather than a bottle alone (Table 4).

\section{Discussion}

The second study illustrates the methodological problems that complicate nutritional research in FTT. The cases in this study displayed two of the characteristics that clinicians commonly expect to find in FTT: low rates of breast-feeding and relative deprivation. Unusually, however, we have an unselected population-based cohort with which to compare 
Table 3. Study 2. Number and variety of foods eaten and energy consumption of children with failure to thrive (cases) and control children from Newcastle city*

(Mean values and standard deviations)

\begin{tabular}{|c|c|c|c|c|c|c|c|c|c|}
\hline & \multicolumn{6}{|c|}{ Crude values } & \multicolumn{3}{|c|}{$\begin{array}{l}\text { Adjusted for significant confounders using } \\
\text { linear regression }\end{array}$} \\
\hline & \multicolumn{2}{|c|}{ Cases } & \multicolumn{2}{|c|}{ Controls } & \multirow{2}{*}{$\begin{array}{c}\text { Mean } \\
\text { difference }\end{array}$} & \multirow{2}{*}{$\begin{array}{c}\text { Statistical } \\
\text { significance of } \\
\text { differencet: } \\
P=\end{array}$} & \multirow{2}{*}{$\begin{array}{c}\text { Mean } \\
\text { difference }\end{array}$} & \multirow{2}{*}{$\begin{array}{c}\text { Other } \\
\text { variables in } \\
\text { model }\end{array}$} & \multirow{2}{*}{$\begin{array}{c}\text { Statistical } \\
\text { significance of } \\
\text { difference: } \\
P=\end{array}$} \\
\hline & Mean & SD & Mean & SD & & & & & \\
\hline \multicolumn{10}{|l|}{ No. of foods: } \\
\hline In diary & $20 \cdot 2$ & $6 \cdot 3$ & $24 \cdot 8$ & $7 \cdot 2$ & $-4 \cdot 6$ & 0.003 & $-3 \cdot 9$ & Age & 0.006 \\
\hline On food frequency & $23 \cdot 9$ & $7 \cdot 1$ & $27 \cdot 8$ & $5 \cdot 5$ & $-3 \cdot 9$ & 0.006 & $-2 \cdot 5$ & Age & 0.048 \\
\hline \multicolumn{10}{|l|}{$\begin{array}{l}\text { Energy intake }(\mathrm{kJ} / \mathrm{kg}) \\
\text { based on: }\end{array}$} \\
\hline Actual wt & 536 & 205 & 469 & 109 & $67 \cdot 0$ & 0.07 & $48 \cdot 2$ & Deprivation & $0 \cdot 18$ \\
\hline Wt-for-height & 473 & 163 & 473 & 109 & 0.0 & 0.99 & $-21 \cdot 0$ & Deprivation & 0.5 \\
\hline Predicted wt & 444 & 155 & 482 & 101 & $-37 \cdot 7$ & $0 \cdot 2$ & -54.5 & Deprivation & 0.06 \\
\hline
\end{tabular}

*For details of subjects and procedures, see p. 41 and Table 2.

$\dagger t$ test.

Table 4. Study 2. Feeding history of children with failure to thrive (cases) and control children from Newcastle city*

\begin{tabular}{|c|c|c|c|c|c|c|c|c|c|}
\hline & \multicolumn{2}{|c|}{ Cases } & \multicolumn{2}{|c|}{ Controls } & \multirow{2}{*}{$\begin{array}{c}\text { Statistical } \\
\text { significance of } \\
\text { difference: } \\
P=\end{array}$} & \multirow{2}{*}{$\begin{array}{c}\text { Crude } \\
\text { OR }\end{array}$} & \multirow{2}{*}{$\begin{array}{c}\text { Adjusted } \\
\text { OR }\end{array}$} & \multirow{2}{*}{$\begin{array}{c}\text { Statistical } \\
\text { significance of } \\
\text { difference: } \\
P=\end{array}$} & \multirow{2}{*}{$\begin{array}{c}\text { Other variables in } \\
\text { model }\end{array}$} \\
\hline & No. & $\%$ total & No. & $\%$ total & & & & & \\
\hline & 13 & 30 & 5 & 11 & 0.03 & $3 \cdot 35$ & 2 & 0.26 & Breast-fed \\
\hline \multicolumn{9}{|l|}{ At meals (mostly)†: } & Breast-fed \\
\hline Eats all & 18 & 42 & 29 & 64 & 0.033 & 0.4 & - & - & None \\
\hline Child enjoys & 31 & 72 & 39 & 87 & $0 \cdot 13$ & 0.43 & - & - & None \\
\hline Mother enjoys & 24 & 56 & 32 & 71 & 0.05 & 0.43 & 0.47 & $0 \cdot 12$ & Breast-fed \\
\hline Drinks from beaker & 18 & 45 & 31 & 72 & 0.012 & 0.32 & 0.36 & 0.042 & Breast-fed \\
\hline
\end{tabular}

OR, odds ratio.

* Forty-four cases, forty-five controls. Responses missing for some variables for up two cases. For details of subjects and procedures, see p. 41 and Table 2. † Parental ratings dichotomized as always or mostly $v$. rarely or never.

these children. From this comparison we know that deprivation levels and breast-feeding rates were no different between unselected case children and the general population from which they were drawn. Thus, these case children must have been subject to some degree of referral bias, with health visitors seemingly less likely to refer breast-feeding mothers. Even more striking, the control children were also not representative of the general population, being markedly less deprived than local norms and more likely to breast-feed. This finding illustrates the fact that when recruiting mothers to a research study there is more likelihood of including 'super mums' rather than lessaffluent or motivated mothers.

Adjusting for this bias is crucial, as what individuals eat and how they describe it is likely to reflect social differences. However, we had a reasonable amount of information on deprivation, and could allow for this deprivation in the multivariate analysis. This analysis revealed that even after adjustment there were persisting differences in the child's eating style, the number and variety of foods taken, and progression onto more mature modes of feeding. The other methodological issue powerfully illustrated by this study is the unreliability of energy estimates in assessing children with FTT. Despite a number of significant differences between case and control children in described feeding behaviour, we were unable to detect a significant difference in energy intake. Nelson (1995) has pointed out that most dietary assessment methods are fraught with error, even in adults. In children with FTT the potential sources of error are further multiplied. All children tend to have variable and irregular eating patterns, and parents of children with FTT, feeling under scrutiny, may describe the ideal rather than the real situation. Some children with FTT will show rapid catch-up, even while awaiting assessment, implying a rapid and substantial change in energy intake. The diaries for such children would thus show high intakes, even though only a few weeks earlier their intake may have been very low. Finally, in a few case children, diaries may have been entirely fabricated, and in these diaries the reported energy intake is likely to be exceptionally high. It is of note that the standard deviation for energy intake of the case children was nearly double that of the controls, reflecting a much wider 
range of intakes. In clinical practice food diaries are invaluable as a guide to the range of foods that might be available in a household, the style of feeding and meal routines, and the families' own ideas about what should be eaten. However, as a means of generating nutrient totals the diaries may be actively misleading.

This leads on to the question of how big a difference we could expect, and whether we could realistically have detected it. The numbers in this study were only sufficient to detect a difference of just under 1SD of energy intake, which for the control children was equivalent to $20-25 \%$ of their average intake, while in case children it was nearer onethird. At the age when these children were assessed they would mainly have been tracking a low centile, rather than dropping away: in the earlier cohort the fall nearly always took place in the early weeks. Thus, only a very small continuing energy deficit might be required to maintain that low centile position, the detection of which would probably require a much larger study. It is of interest that despite these limitations the number of foods shown on the diary was significantly lower $(P=0.003)$ for case children, a finding that was replicated in the food-frequency table $(P=0.006)$. An observational study in the developing world found that there was a correlation between the number of times a child ate daily with total energy intake (Garcia et al. 1990).

\section{Conclusion}

There are important messages from these studies, both about the nature of FTT and the practicalities of research. The first study, although limited in its scope, supplied invaluable information about the demographic profile of unselected children with FTT. As such it suggests that FTT is not primarily a problem of deprivation and neglect. This finding is supported by other population-based studies. Skuse et al. (1992) found that mothers of infants with FTT were no more deprived than local controls, and also found similarly low rates of abuse and neglect (Skuse et al. 1995). Despite these findings, the dietary information collected for the case children strongly suggests an underlying nutritional cause. These data cannot be compared with control data, but it is of note that there was a significant correlation between the overall nutrition score and BMI $(R \quad 0.28, \quad P<0.05)$. Moreover, the limited case-control information suggests that one contribution to this undernutrition is a lack of interest in food on the part of the child.

The second study provided further indications of the role of diminished appetite and vigour of eating style in the child. It also suggested that the children with FTT eat a reduced number and variety of foods, and progress onto feeding on solids more slowly. What cannot be elucidated from either of these studies is whether these characteristics are a cause or an effect of their FTT, or indeed whether they genuinely reflect the child's behaviour or simply the parental interpretation of it. However, there is a suggestion from our randomized controlled trial that children who receive intervention go on to have a better appetite, as well as better weight gain (Wright, 1998b).

The messages to researchers from these studies may be important. They illustrate just how difficult and complicated nutritional research is when it is applied to free-living animals such as babies. They suggest in particular that the case-control approach to the study of FTT may be seriously flawed. Unless controls can be recruited from some easilyaccessed sampling frame, with high levels of compliance, they are unlikely to be sufficiently representative of the general population to be informative. The case-control model was developed for studying biological risk factors. We would argue that it is much less suitable when applied to social characteristics such as dietary behaviour. The findings also suggest that the process of attempting to collect robust and consistent information may itself distort the very dietary information that is required. We argue that while invaluable qualitative information can be collected from food diaries and from surveys, precise measurement of nutritional intake may not be possible.

\section{Acknowledgements}

We are grateful to Chris Aves for her invaluable work on the dietary assessment data in study 1, to Lynn Spence for her help with data collection in study 2, to all the Health Visitors in Newcastle City Health for their invaluable assistance, and all the families for taking part.

\section{References}

Batchelor J \& Kerslake A (1990) Failure to Find Failure to Thrive. London: Whiting and Bush.

Bithoney WG, McJunkin J, Mchalek J, Egan H, Synder \& Munier A (1989) Prospective evaluation of weight gain in both nonorganic and organic failure to thrive children: an outpatient trial of a multidisciplinary team intervention strategy. Developmental and Behavioral Pediatrics 10, 27-31.

Black MM, Dubowitz H, Hutcheson J, Berenson-Howard J \& Starr RH (1995) A randomized clinical trial of home intervention for children with failure to thrive. Pediatrics 95, 807-814.

Department of Health (1994) Weaning and the Weaning Diet. Report on Health and Social Subjects no. 45. London: H.M. Stationery Office.

Dowdney L, Skuse D, Heptinstall E, Puckering C \& Zur-Szpiro S (1987) Growth retardation and developmental delay among inner-city children. Journal of Child Psychology and Psychiatry 28, 529-541.

Drotar D, Malone CA, Devost L, Brickell C, Mantz-Clumpner C, Negray J, Wallace M, Woychick J, Wyatt B, Eckerle D, Bush M, Finlon M, El-Amin D, Nowak M \& Satola J (1985) Early preventive intervention in failure to thrive: methods and preliminary outcome. In New Developments in Failure to Thrive, pp. 119-138 [D Drotar, editor]. New York: Plenum Press.

Drotar D \& Sturm L (1988) Prediction of intellectual development in young children with early histories of non-organic failure to thrive. Journal of Pediatric Psychology 13, 281-296.

Fletcher L (1994) Microdiet. Salford: University of Salford.

Foster K, Laider D \& Cheesbrough S (1997) Infant Feeding 1995. London: H.M. Stationery Office.

Freeman JV, Cole TJ, Chinn S, Jones PRM, White EM \& Preece MA (1995) Cross sectional stature and weight reference curves for the UK, 1990. Archives of Disease in Childhood 73, $17-24$.

Garcia SE, Kaiser LL \& Dewey KG (1990) The relationship of eating frequency and caloric density to energy intake among rural Mexican pre-school children. European Journal of Clinical Nutrition 44, 381-387. 
Heptinstall E, Puckering C, Skuse D, Start K, Zur-Szpiro S \& Dowdney L (1987) Nutrition and meal time behaviour in families of growth-retarded children. Human Nutrition: Applied Nutrition 41A, 390-402.

Nelson M (1995) Editorial - can we measure what people eat? Journal of Human Nutrition and Dietetics 8, 1-2.

Office of Population Censuses and Surveys (1992) 1991 Census. County Report: Tyne and Wear, part 1. London: H.M. Stationery Office.

Pollitt E \& Leibel R (1980) Biological and social correlates of failure to thrive. In Social and Biological Predictors of Nutritional Status. Physical Growth and Neurological Development, pp. 173-200 [LS Greene and FE Johnston, editors]. New York: Academic Press.

Skuse D (1985) Non-organic failure to thrive: a reappraisal. Archives of Disease in Childhood 60, 173-178.

Skuse D, Gill D, Reilly S, Wolke D \& Lynch M (1995) Failure to thrive and the risk of child abuse: a prospective population study. Journal of Medical Screening 2, 145-149.

Skuse D, Reilly S \& Wolke D (1994) Psychosocial adversity and growth during infancy. European Journal of Clinical Nutrition 47, Suppl. 1, 113-130.
Skuse D, Wolke D \& Reilly S (1992) Failure to thrive: clinical and developmental aspects. In Developmental Psychopathology, pp. 46-71 [H Remschmidt and MH Schmidt, editors]. Lewiston, NY: Hogrefe \& Huber.

Wilensky D, Ginsberg G, Altman M, Tulchinsky T, Yishay F \& Auerbach J (1996) A community based study of failure to thrive in Israel. Archives of Disease in Childhood 75, 145-148.

Wright C, Avery A, Epstein M, Birks E \& Croft D (1998a) New chart to evaluate weight faltering. Archives of Disease in Childhood 78, 40-43.

Wright C \& Birks E (1999) Risk factors for failure to thrive: a population based survey. Child Care Health and Development (In the Press).

Wright C, Callum J, Birks E \& Jarvis S (1998b) Community based management of failure to thrive: a randomised control trial. British Medical Journal 317, 571-574.

Wright CM, Waterston A, Matthews JNS \& Aynsley-Green A (1994) What is the normal rate of weight gain in infancy? Acta Paediatrica 83, 351-356. 